\title{
BASES DEL CAMBIO DE LA MATRIZ PRODUCTIVA
}

Se denomina matriz productiva al conjunto interactuante e interrelacionado existente entre los distintos actores sociales que desarrollan actividades productivas enlazadas directamente con productos, procesos productivos y relaciones sociales; es decir, la forma como se organiza la sociedad para producir determinados bienes y servicios relacionando a sus involucrados, tendientes a establecer patrones de especialización.

Con la transformación del patrón de especialización; que es el cambio de la producción primaria exportadora, hacia la producción diversificada con mayor valor agregado, conocimiento y biodiversidad se logrará establecer la presencia ecuatoriana alrededor del mundo.

La finalidad del cambio de la Matriz Productiva es generar un mayor valor agregado a la economía productiva del país a través de la construcción de una sociedad del conocimiento. Se fundamenta en transformar el modelo de generación de riqueza, pasando de sus características concentradoras, excluyentes y basadas en recursos naturales; hacia un enfoque democrático, incluyente y fundamentado en el conocimiento y capacidades de los ecuatorianos.

Según el Folleto Informativo I, Revolución productiva a través del conocimiento y el talento humano, los ejes para la transformación de la matriz productiva son:

1. Diversificación productiva basada en el desarrollo de industrias estratégicas-refinería, astillero, petroquímica, metalurgia y siderúrgica y en el establecimiento de nuevas actividades productivas-maricultura, biocombustibles, productos forestales de madera que amplíen la oferta de productos ecuatorianos y reduzcan la dependencia del país.

2. Agregación de valor en la producción existente mediante la incorporación de tecnología y conocimiento en los actuales procesos productivos de biotecnología (bioquímica y biomedicina), servicios ambientales y energías renovables.

3. Sustitución selectiva de importaciones con bienes y servicios que ya actualmente son producidos, pero que se pueden sustituir en el corto plazo: industria farmacéutica, tecnología (software, hardware y servicios informáticos) y metalmecánica.
4. Fomento a las exportaciones de productos nuevos, provenientes de actores nuevos; particularmente de la economía popular y solidaria, o que incluyan mayor valor agregado en los sectores de alimentos frescos y procesados, turismo, confecciones y calzado. Con el fomento a las exportaciones buscamos también diversificar y ampliar los destinos internacionales de nuestros productos. Secretaría Nacional de Planificación y Desarrollo. (2012).

Lo que se busca es organizar la producción partiendo del conocimiento y las relaciones sociales generando sostenibilidad en el mundo. Razón por la cual la Secretaría Nacional de Planificación y Desarrollo (SENPLADES) y todos sus stakeholders, han identificado 14 sectores productivos y 5 industrias estratégicas para el proceso de cambio de la matriz productiva del Ecuador, facilitando la efectiva interrelación entre la políticas públicas y sus áreas de intervención con las industrias.

\section{Industrias consideradas en la Matriz Productiva, según Sectores}

\section{SEQTORES IIDUSTRIAS}

\begin{tabular}{|c|c|}
\hline \multirow{8}{*}{ 誓 } & 1) Alimentos frescos y procesados \\
\hline & 2) Biotecnología (bioquímica y biomedicina) \\
\hline & 3) Confecciones y calzado \\
\hline & 4) Energías renovales \\
\hline & 5) Industria Farmacéutica \\
\hline & 6) Metalmecánica \\
\hline & 7) Petroquímica \\
\hline & 8) Productos forestales de madera \\
\hline \multirow{6}{*}{$\begin{array}{l}\text { 吕 } \\
\text { 咅 }\end{array}$} & 9) Servicios ambientales \\
\hline & $\begin{array}{l}\text { 10) Tecnología (software, hardware y servicios in- } \\
\text { formáticos) }\end{array}$ \\
\hline & 11) Vehículos, automotores, carrocerías y partes \\
\hline & 12) Construcción \\
\hline & 13) Transporte y logística \\
\hline & 14) Turismo \\
\hline
\end{tabular}

Fuente: SENPLADES

Elaboración: Equipo Técnico del Observatorio Económico y Social de Tungurahua 
Industrias Estratégicas consideradas en la Matriz Productiva

\begin{tabular}{|c|l|l|}
\hline \multicolumn{3}{|c|}{ INDUSTRAAS EOTRATÍ⿴囗十⺝CAS } \\
\hline Industria & Posibles bienes o servicios & Proyectos \\
\hline Refinería & $\begin{array}{l}\text { Metano, butano, propano, } \\
\text { gasolina, queroseno, gasoil }\end{array}$ & Refinería del Pacífico \\
\hline Astillero & $\begin{array}{l}\text { Construcción y reparación } \\
\text { de barcos, servicios } \\
\text { asociados }\end{array}$ & $\begin{array}{l}\text { Implementación de } \\
\text { astillero de Posorja }\end{array}$ \\
\hline Petroquímica & $\begin{array}{l}\text { Urea, pesticidas, herbicidas, } \\
\text { fertilizantes, foliares, } \\
\text { plásticos, fibras sintéticas, } \\
\text { resinas }\end{array}$ & $\begin{array}{l}\text { Estudios para la } \\
\text { producción de urea } \\
\text { yertilizantes nitrogenada } \\
\text { Planta Petroquímica Básica }\end{array}$ \\
\hline Metalurgia \\
(cobre) & $\begin{array}{l}\text { Cables eléctricos, tubos, } \\
\text { laminación }\end{array}$ & $\begin{array}{l}\text { Sistema para la } \\
\text { automatización de } \\
\text { actividades de catastro } \\
\text { seguimiento y control } \\
\text { minero, seguimiento, control } \\
\text { y fiscalización de labores a } \\
\text { gran escala }\end{array}$ \\
\hline Siderúrgica & Planos, largos & $\begin{array}{l}\text { Mapeo geológico a } \\
\text { nivel nacional }\end{array}$ \\
\hline
\end{tabular}

Fuente: SENPLADES

Elaboración: Equipo Técnico del Observatorio Económico y Social de Tungurahua

El vicepresidente de la República, Jorge Glas Espinel en conferencia sobre el cambio de la matriz productiva en la Universidad Técnica de Ambato, manifestó que se debe cambiar esta con la finalidad de establecer la sostenibilidad de la economía en el tiempo sin depender únicamente del petróleo, es fundamental establecer procesos de investigación, innovación, desarrollo e inversión enfocados en la multidiversidad del pensamiento, a lo que denominó "economía del conocimiento".

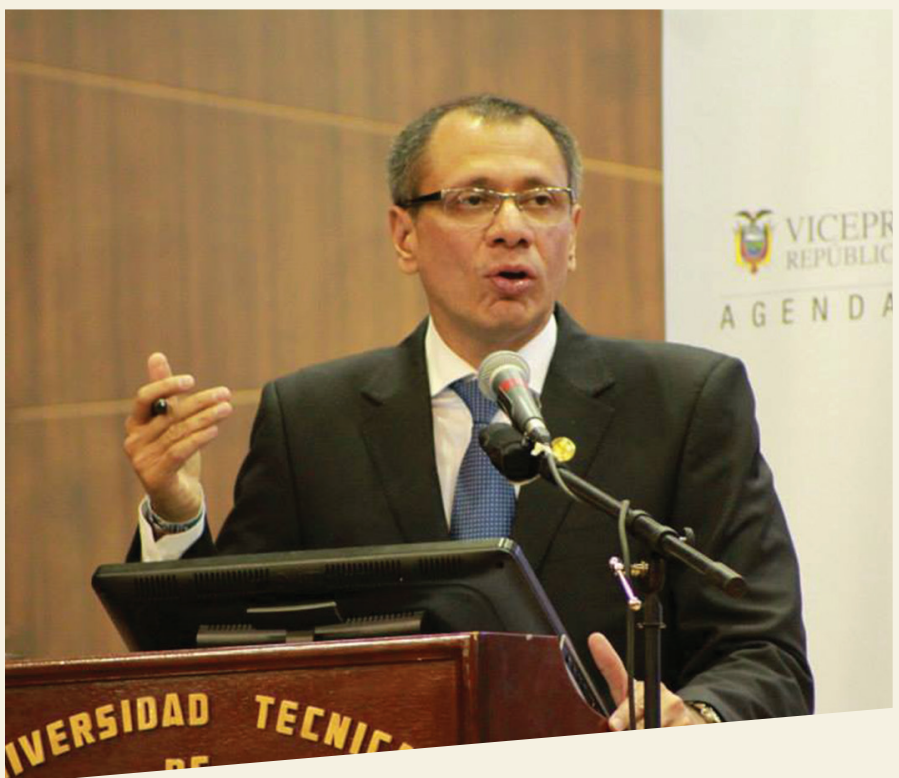

Según el Vicepresidente, el cambio de la matriz productiva permitirá contar con:

- Nuevos esquemas de generación, distribución y redistribución de riqueza.

- Reducción de la vulnerabilidad de la economía ecuatoriana.

- Eliminación de las inequidades territoriales.

- Incorporación de nuevos actores al desarrollo del mercado.

- Generación de riqueza utilizando las capacidades y conocimientos de la población.

Adicionalmente, manifestó que el rol de los sectores estratégicos enfocados en la inversión, el talento humano y la innovación tecnológica pretenden desarrollar infraestructuras, generar empleo, transferir tecnología, consolidar inversiones de sectores estratégicos, mejorar la competitividad sistémica y atraer la inversión nacional e internacional.

Posteriormente, hizo una comparación de cómo se manejaba la matriz productiva anterior en relación con la matriz productiva que se desea obtener, que de forma gráfica se presenta a continuación:

\section{Matriz productiva actual}

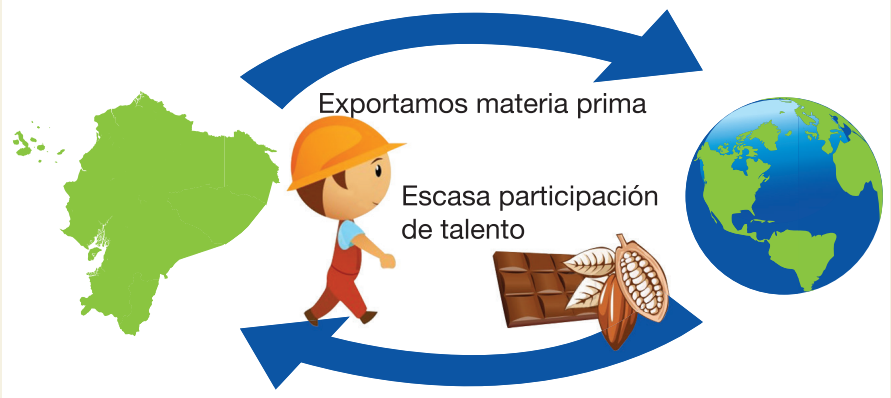

Fuente: SENPLADES

Matriz productiva que se desea obtener

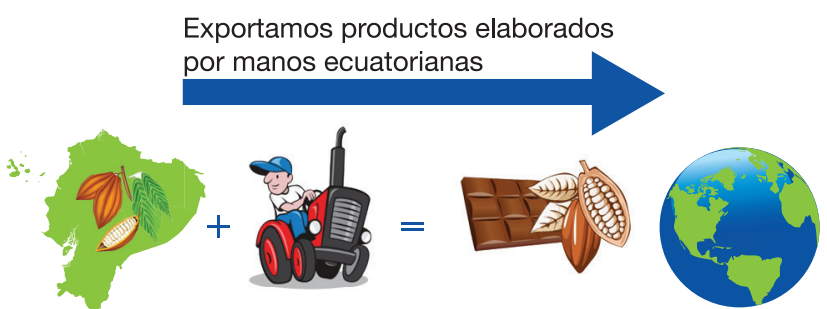

$$
\begin{array}{lll}
\text { Industrias, } & \begin{array}{l}
\text { Plazas de empleo } \\
\text { tecnología participación del }
\end{array} & \begin{array}{l}
\text { Más y mejor } \\
\text { producción } \\
\text { talento humano) }
\end{array}
\end{array}
$$

Fuente: SENPLADES 
Finalmente, se abrió una rueda de preguntas, entre una de ellas planteadas en relación a la Provincia ¿En qué aspectos Tungurahua contribuye en el desarrollo y ejecución de la matriz productiva?, respondió que el porcentaje de contribución de Tungurahua al PIB Nacional es bajo, pero que se puede incrementar a través del desarrollo de cadenas productivas, que en esta zona geográfica se enfocaría en aspectos alimentarios y lácteos tecnificados con centros de acopio; serán necesarias reformas agrarias y la participación directa de la Academia a través de la Universidad Técnica de Ambato. Un ejemplo analizado fue la industrialización de la papa, mediante la generación de harina de papa que sustituya la importación de harina de trigo.

En conclusión, la transformación de la matriz productiva convertirá al país en generador y exportador de mayor valor agregado a través del aprovechamiento del conocimiento y el talento humano ecuatoriano, con inclusión de nuevos actores sobre la base de una adecuada redistribución y equidad, asegurando de esta manera el Buen Vivir para la población actual y la venidera.

\section{Referencias Bibliográficas}

- Secretaria Nacional de Planificación y Desarrollo, SENPLADES. Cambio de la Matriz Productiva.

- Ministerio Coordinador de Sectores Estratégicos, Sectores Estratégicos al cambio de la Matriz Productiva.

- http://www.planificacion.gob.ec/wp-content/uploads/ downloads/2013/01/matriz productiva WEBtodo.pdf

- $\quad$ http://www.ekosnegocios.com/revista/pdfTemas/736.pdf

Observatorio Económico y Social de Tungurahua (OBEST) Universidad Técnica de Ambato.

Ing. César A. Guerrero V.

\section{EL DINERO ELECTRÓNICO}

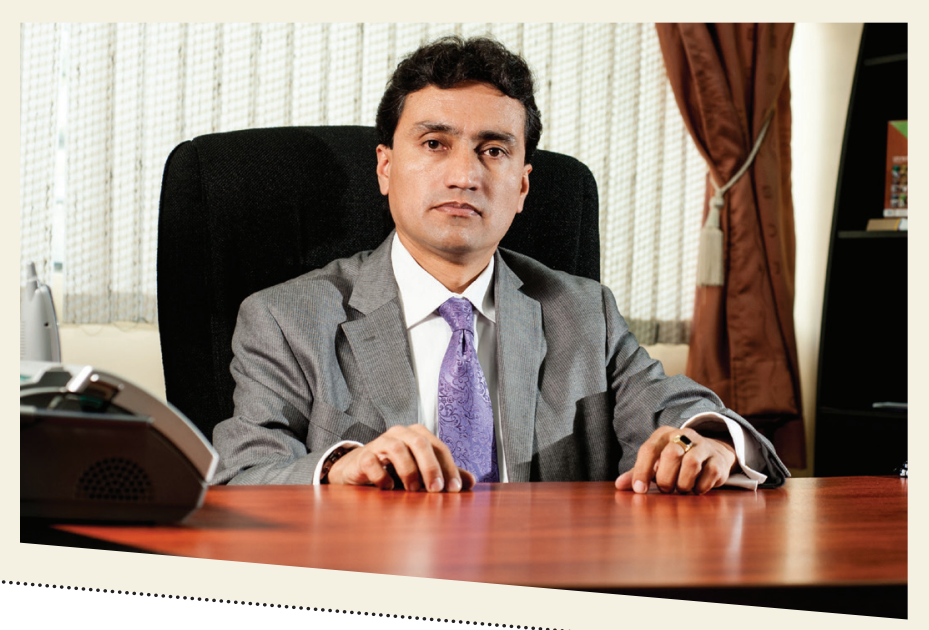

En países industrializados como Estados Unidos, Japón, Canadá, Inglaterra, Alemania, Francia e Italia entre otros, el pago de las transacciones de compra venta de bienes y servicios por pequeños o grandes que sean, se lo hace a través de una tarjeta de crédito, de débito o cheque, por ejemplo pagar el parqueo, la compra de una hamburguesa, de un pantalón, del combustible, sólo para citar algunos casos, facilitando la negociación en forma segura, ágil y exacta en tiempo real sin la necesidad de la presencia física del dinero; de hecho, casi el $80 \%$ de las transacciones en esos países se efectúan así porque en todo lugar prefieren ejecutar los pagos y cobros mediante estos mecanismos electrónicos, al contrario de nuestras economías tradicionalistas que no estamos seguros si no vemos y tenemos en nuestras manos las monedas y billetes. 